\title{
II PND, O POLOCENTRO E O DESENVOLVIMENTO DO ESTADO DE GOIÁS
}

${ }^{1}$ Economista, Acadêmico do Mestrado em Territórios e Expressões Culturais do Cerrado (TECCER) - Linha: Dinâmica Territorial do Cerrado - Universidade Estadual de Goiás (UEG) - marcio.dourado@ueg.br ${ }^{2}$ Doutora em História, Docente de Ensino Superior - TECCER / UEG - dportilho@uol.com.br ${ }^{3}$ Doutora em Economia, Docente de Ensino Superior - TECCER / UEG - divalunas@gmail.com

\section{Recebido em: 30/05/2014 - Aprovado em: 30/06/2014 - Disponibilizado em: 30/07/2014}

\begin{abstract}
Resumo:
O presente artigo analisa a atual dinâmica econômica do estado de Goiás e o seu nível de desenvolvimento. Baseia-se em informações que comprovam que estado de Goiás se tornou um economia dinâmica que se destaca no cenário brasileiro. Correlaciona dados atuais e históricos da economia deste estado com políticas de integração do território e desenvolvimento econômico do regime militar. Analisa especificamente o II PND e o POLOCENTRO. O estudo tem como método a pesquisa bibliográfica e estatística. Descreve o papel da agricultura como dinamizadora da economia do estado, isolando as demais variáveis. Fundamenta-se nos dados e na bibliografia para comprovar a afirmação de que o atual nível de desenvolvimento e a posição de destaque do crescimento econômico vivido atualmente deriva diretamente da implementação do POLOCENTRO. É dividido em partes que discutem o dinamismo do setor agrícola da economia do estado de Goiás em períodos que antecedem a década de 1970, foca especificamente neste período e finalmente trata da economia goiana recente. Apresenta dados numéricos em tabelas e gráficos. Faz considerações finais em que testa a hipótese e demonstra alternativa para aumento da produção agropecuária e geração de riqueza quanto a dinâmica do uso do solo goiano.
\end{abstract}

Palavras Chave: POLOCENTRO. Planejamento Estatal. Setor Agrícola. Vocação Regional. Desenvolvimento.

\section{ND PND, THE POLOCENTRO AND THE STATE OF GOIAS DEVELOPMENT}

\begin{abstract}
:
The present article analyzes the actual dynamic economy of The State of Goias, and its development level. It is based in information that can prove that Goias became a State with dynamic economy, which stands out, in the Brazilian scene. Correlates current historical data in The State of Goias economy with territory politics integration and military economic development. It is focused specifically about the II PND and the POLOCENTRO. It uses bibliographic and statistic research. It Analyses the agriculture role like the State economy proactive, isolating the other variables. Furthermore, analyses using the data and bibliography reasons, the statement that the actual level of development and the prominent position of the economic growth actually lived is directly steamed from the POLOCENTRO implementation. It is divided in pieces that discuss the dynamism of the agricultural sector economy in the State of Goias in periods that precedes the 1970 's, it focus in the date and finally treat the economy nowadays. The article presents numeric dates in tables and graphs. It makes final considerations, which tests the hypothesis and shows alternative to the growth of agricultural production and wealth generation.
\end{abstract}

keywords: POLOCENTRO. State Planning. Agricultural Sector. Regional Vocation. development. 


\section{Introdução}

O estado de Goiás ocupa hoje posição de destaque no cenário nacional, figurando como o $9^{\circ}$ maior produto interno bruto entre as unidades da federação brasileira e apresentando constantes taxas de crescimento

superior a média nacional (IMB/SEGPLAN 2012), porém, a economia goiana nem sempre foi apontada como algo promissor, tampouco o estado figurava entre as economias mais pujantes ou dinâmicas até a década de 1970. Esta situação mudou consideravelmente com a implantação de políticas governamentais de modernização da agricultura e desconcentração regional, a partir de programas estratégicos de desenvolvimento regional e setorial, além de mecanismos fiscais e financeiros para atrair capitais para regiões atrasadas frente às demais regiões historicamente mais desenvolvidas e com maior volume de atividade econômica, promovendo assim um maior equilíbrio de atividade econômica entre as regiões do país.

O território ocupado pelo estado de Goiás, desde seu desmembramento da capitania de São Paulo no século XVIII, teve sua dinâmica econômica dividida em fases de relativos picos de desenvolvimento, sendo inicialmente marcados pela intensificação da atividade mineradora na primeira metade do século XVIII, posteriormente pela construção das cidades de Goiânia e Brasília, e mais tarde pelo aprimoramento de técnicas de cultivo e uso do solo que transformaram a região do cerrado brasileiro em um grande celeiro de produção agrícola altamente tecnificada.

No contexto de planejamento regional, os governos militares deram espaço para a implantação de políticas de planejamento que visavam entre outros objetivos, a integração do território nacional e a diminuição dos desequilíbrios regionais.

Para a região Centro-Oeste, em especial para o estado de Goiás, o plano de maior impacto no seu desenvolvimento foi o II PND, através do Programa de Desenvolvimento dos Cerrados (POLOCENTRO) como o principal instrumento de incentivo governamental para o Cerrado.

$\mathrm{O}$ presente artigo analisar o desenvolvimento do Estado de Goiás focando especificamente no período que se antecedeu à implantação dos incentivos praticados pelo plano II PND, sobretudo pelo POLOCENTRO, as formas de atuação do plano e especificamente do programa e finalmente as principais transformações com sua implementação, focando nos aspectos econômicos no que tange à intensificação da agricultura comercial no território goiano e consequente dinamização da economia local e sua inserção no cenário nacional e internacional. Não foram analisadas 
especificamente as questões sociais ou ambientais.

Assume a premissa do estado de Goiás como um estado que tem sua economia voltada para o setor agrícola ou dele é dependente, procurando isolar as demais variáveis que interferiram no seu processo de desenvolvimento.

Tendo como problema de pesquisa a questão: "quais foram as contribuições do POLOCENTRO para a atual dinâmica econômica do estado de Goiás?” testando a hipótese de que o dinamismo econômico do estado de Goiás dependeu significativamente deste programa para sua ocorrência.

O presente trabalho utiliza pesquisa bibliográfica e de bases de dados disponibilizadas pelo Instituto Brasileiro de Geografia e Estatística (IBGE) e pela Secretaria de Gestão e Planejamento do Estado de Goiás (SEGPLAN), procurando sempre que possível, confrontar os dados obtidos com a bibliografia existente sobre o assunto abordado.

\section{A Economia Goiana antes do II PND}

A primeira fase do desenvolvimento econômico do estado de Goiás perdurou do início da exploração mineral, no século XVIII até o final do século XIX, quando mesmo sendo a atividade mineradora o carro chefe da economia, havia produção agropecuária, sendo que conforme Simonsen (1978:150), a criação de gado configurou-se como "um decidido apoio à mineração, fixador do povoamento no interior e objeto de grandes correntes de comércio que se estabeleceram dentro do país”, porém com a diminuição das atividades mineradoras, a pecuária continuou a exercer seu papel, com um processo rudimentar de produção, sendo que a riqueza gerada por tal atividade era integradora do território, por oferecer condições de troca de valores e mercadorias em uma época de baixa liquidez econômica, mas o isolamento caracterizava verdadeiras "ilhas" dentro do território, conforme observado por Estevam (1997):

No final do século XIX, Goiás configurava um mosaico de diferenciadas 'ilhas' de moradores no alongado território. A vasta superfície, ao garantir um espaço de fronteiras abertas voltado para a periferia de outras províncias, foi absorvendo, de cada uma delas, o entrelaçamento e a convivência... Existiam relações inter-regionais com as comunidades mais próximas, mas não intraregional, sendo que os precários caminhos dificultavam ou mesmo impediam a comunicação das localidades nortistas com as sulistas. (ESTEVAM 1997; p. 37)

Após a instalação da estrada de ferro em Goiás, o estado passou a ter áreas de distintas características de dinâmicas econômicas e de integração do mercado, o 
que também tornaria injusta uma generalização de todo o estado ou região como um vazio improdutivo ou uma "Terra de Ninguém”, conforme observado por Leme e Guimarães:

Esse processo segmentou nitidamente o Estado de Goiás em três áreas distintas, do ponto de vista da dinâmica econômica e da integração ao mercado. As zonas sudoeste e sul, em franco processo de ocupação e expansão produtiva. A zona centro-sul, integrada diretamente à ferrovia, experimentando uma transformação nas suas relações de produção, substituindo parcialmente a pecuária extensiva pela lavoura e iniciando um processo de acumulação mercantil e diversificação da estrutura produtiva. Por fim, o sudeste do estado, na letargia de sua marginalização das rotas comerciais e conseqüente enfraquecimento urbano. (LEME E GUIMARÃES, 1997)

Para Leme e Guimarães (1997), a revolução de 1930 marcou o fim da República Velha e o início de um novo padrão de acumulação urbano-industrial que trouxe mudanças na atuação do Estado, criando condições para a expansão do mercado interno, estimulando a demanda por alimentos e criando vínculos com área de produção agropecuária, fazendo com que a região Centro-Oeste tivesse maior presença na vida nacional e sua oferta de terras estimulasse a "penetração de colonos do Sul e Sudeste no território Goiano", o que ficou marcado como um período de intensa ocupação do território de Goiás.

Posteriormente, já na década de 1950 , o Plano de Metas, que tinha como meta síntese a construção de Brasília, foi outro marco decisivo para a inserção do estado de Goiás no cenário produtivo nacional, sua implantação acelerou consideravelmente os fluxos migratórios, incrementando o ainda modesto, mas já relevante mercado consumidor da região e trazendo melhorias significativas em infraestrutura de transporte e comunicações, que seriam vitais para a consolidação do estado como potência agrícola.

Salvo algumas experiências bem sucedidas de colonização e intensificação de produção agrícola, a economia do estado de Goiás no início da década de 1970 focava-se basicamente na pecuária extensiva, com pouca utilização de capital, e apesar de já apresentar alguma dinâmica pela aceleração da urbanização trazida pela construção de Goiânia e mais tarde de Brasília, ainda apresentava poucos resultados frente o seu potencial e quantidade de terras disponíveis.

O potencial inexplorado pela lavoura pode ser observado na Tabela 01, que aponta que entre os anos de 1970 e 1980, a utilização das terras com lavouras temporárias, onde normalmente se insere a profissionalização da agricultura voltada, sobretudo para a produção de grãos, mais que dobrou, sem 
causar detrimento às outras atividades agropecuárias praticadas no Estado de Goiás, segundo o levantamento do IBGE.

Tabela 01 - Goiás - Utilização das Terras (ha) 1970-1980

\begin{tabular}{l|l|l|l}
\hline \multicolumn{1}{c|}{$\begin{array}{c}\text { Tipo de } \\
\text { Atividade }\end{array}$} & \multicolumn{1}{c|}{$\mathbf{1 9 7 0}$} & $\mathbf{1 9 7 5}$ & $\mathbf{1 9 8 0}$ \\
\hline $\begin{array}{l}\text { Lavouras } \\
\text { permanentes }\end{array}$ & 78.454 & 76.744 & 121.980 \\
\hline $\begin{array}{l}\text { Lavouras } \\
\text { temporárias }\end{array}$ & 1.557 .711 & 2.484 .350 & 3.104 .289 \\
\hline $\begin{array}{l}\text { Pastagens } \\
\text { naturais }\end{array}$ & 19.423 .118 & 21.712 .529 & 20.578 .467 \\
\hline $\begin{array}{l}\text { Pastagens } \\
\text { plantadas }\end{array}$ & 4.362 .064 & 7.451 .634 & 10.843 .662 \\
\hline $\begin{array}{l}\text { Matas } \\
\text { naturais }\end{array}$ & 4.911 .062 & 6.369 .257 & 6.888 .654 \\
\hline $\begin{array}{l}\text { Matas } \\
\text { plantadas }\end{array}$ & 24.598 & 24.799 & 78.601 \\
\hline & 30.358 .977 & 38.121 .288 & 41.617 .633 \\
\hline Total & & & \\
\hline Fonte: IBGE & Censo Agropecuant0 1920 & 2006. \\
\hline
\end{tabular}

Fonte: IBGE, Censo Agropecuário 1920/2006. Organização: Da pesquisa

A pouca utilização do território goiano na produção intensiva de produtos primários diante da vastidão do seu território, explicitava vazios improdutivos, onde havia domínio da pecuária extensiva, em pastagens naturais geralmente degradadas e com pouquíssima ou nenhuma utilização de capital fixo na produção, o que ainda trazia um sentimento de "Terra de ninguém" para muitos rincões do interior goiano.

\section{O II PND e o POLOCENTRO}

A realidade da agricultura goiana apresentou novos horizontes a partir de iniciativas governamentais de planejamento e ocupação do território, através de políticas que priorizaram a agricultura, setor este que possuía grande potencial de desenvolvimento no estado de Goiás, que dispunha de vastas terras e água em abundância para sua intensificação.

Compondo o arcabouço de planejamento desenvolvimentista dos governos militares, houve a implantação do II Plano Nacional de Desenvolvimento (II PND), formulado em 1974 para o período 1975-1979, que priorizou o desenvolvimento do capitalismo no campo.

O plano apontava a necessidade de mudança do papel da agricultura na estratégia nacional de desenvolvimento, de modo a fornecer alimentos e matérias primas necessários à crescente população sem a elevação do preço real.

A mudança do papel da agricultura exigia muito mais do setor agropecuário e colocava a ocupação de novas áreas, segundo o II PND, “como processo importante de expansão da agricultura, dada a existência de terras relativamente férteis para deslocamento da fronteira agrícola", aproveitando assim a estrutura viária recém construída e que dava acesso às "imensas áreas no Centro-Oeste e na Amazônia".

O plano frisava a necessidade de consolidação e diversificação das vocações naturais e a grande variedade de fatores de produção existentes no Brasil, dadas as suas 
dimensões continentais, e para atingir tal intento, traçava uma estratégia de investimentos e difusão tecnológica:

A estratégia agrícola está orientada no sentido de criar as facilidades e dotar o setor de investimentos para o pleno aproveitamento de seu potencial produtivo: ampliar o estoque de recursos produtivos pela atração de poupanças (internas e externas) e capacidade empresarial para as atividades diretamente ligadas à produção; estimular a participação mais intensa do setor privado para as funções de serviços de apoio à produção, circulação e transformação dos produtos agropecuários; dinamizar o processo de criação, importação, adaptação e difusão de tecnologia às peculiaridades regionais.

(República Federativa do Brasil. Projeto do II Plano Nacional de Desenvolvimento II PND (1975-1979), Brasília, 1974, pp. 33-34. Apud. Duarte, 2009, 162163).

Como estratégia do II PND na região do Cerrado brasileiro, foi instituído, através do Decreto n. 75.320 de 29/01/1975, o Programa de Desenvolvimento dos Cerrados - POLOCENTRO, com o objetivo explícito de ocupar os cerrados brasileiros de maneira "racional".

Art. $1^{\mathrm{o}}$ - É criado o Programa de Desenvolvimento dos Cerrados (POLOCENTRO), com o objetivo de promover o desenvolvimento e a modernização das atividades agropecuárias no Centro-Oeste e no Oeste do Estado de Minas
Gerais, mediante a ocupação racional de áreas selecionadas, com características de cerrado. Decreto 75.320/75 - Casa Civil da Presidência da República

A ação do programa constituía na seleção de pólos de desenvolvimento agropecuário em áreas estratégicas, com alguma infraestrutura e potencial agrícola favorável, difundindo técnicas e inovações para as demais áreas e estimulando a capitalização da agricultura, sendo que foram selecionadas 12 áreas prioritárias e 5 das quais se localizavam no estado de Goiás.

A análise do material técnico sobre o POLOCENTRO demonstra que o mesmo era um programa que tinha por objetivo o desenvolvimento por indução, e a sua implantação configurava-se em uma verdadeira aposta tanto para os tomadores de crédito, como para o governo que o fornecia, conforme observado por Alencar (1999):

As razões do POLOCENTRO seriam a de demonstrar a viabilidade econômica de utilização dos cerrados para agropecuária, revelando que a ocupação indiscriminada dessas terras, sem a utilização de tecnologia adequada, envolvia altos riscos, com prejuízos para a economia do País e para empresários agrícolas. Alencar (1979).

O sucesso do POLOCENTRO no estado de Goiás, quanto ao seu objetivo de ocupação para produção intensiva em áreas até então ociosas ou degradadas, evidencia-se pelas informações dispostas no Gráfico 01 , 
onde se observa o considerável aumento da produção absoluta de grãos no estado, dandose especial atenção ao crescimento da produção absoluta de milho e da produção relativa da soja, que em 1970 era incipiente, porém em 10 anos cresceu exponencialmente.

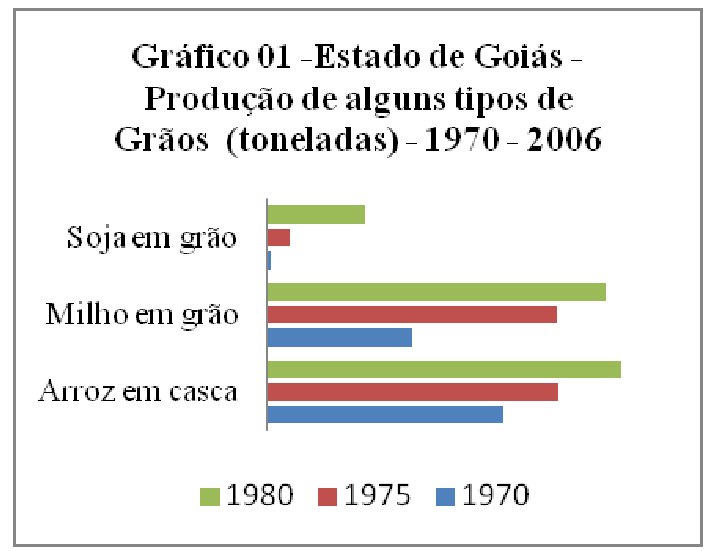

Fonte: IBGE, Censo Agropecuário 1920/2006 Adaptado pelo autor

$\mathrm{Na}$ produção animal, em especial na pecuária bovina, os impactos positivos da implantação do POLOCENTRO não foram diferentes, dados do censo agropecuário do IBGE apontam um aumento do rebanho bovino de pouco mais de 7 milhões de cabeças de gado em 1970, para mais de dezesseis milhões em 1980, a produção de leite de vaca, por sua vez, praticamente triplica na mesma década.

Com o sucesso do POLOCENTRO, pode-se afirmar que Goiás se consolida como um importante gerador de divisas agrícolas no Brasil, com a agricultura sendo uma área dinâmica de geração de riquezas. O processo de acumulação e internacionalização deste setor criou condições para o financiamento de outros setores da economia, sobretudo a agroindustrialização.

O II PND também procurou desconcentrar a indústria brasileira, e no estado de Goiás incentivou a criação de distritos industriais, focados especialmente no aproveitamento da proximidade das regiões produtoras, incentivando as agroindústrias que com a intensificação de incentivos fiscais, mais tarde induziram a intensificação de produção de outros tipos de produtos secundários.

\section{A Agropecuária na Economia}

\section{Goiana no Século XXI e sua} relação com o POLOCENTRO

Salienta-se que em 2012 a economia do estado de Goiás classifica-se em nono lugar entre os estados brasileiros no ranking do Produto Interno Bruto, sendo também o $4^{\circ}$ maior produtor de grãos (IBGE-2012) e possuindo o $3^{\circ}$ maior rebanho bovino do país.

Devido às condições logísticas e à grande produção do setor primário, no setor secundário, o estado de Goiás se destaca na agroindústria, especialmente no beneficiamento e industrialização de grãos, carnes e leite. Indústrias de ramos diversos ao agronegócio também foram atraídas para Goiás através de agressiva política de incentivos fiscais praticada desde meados da década de 1980, porém a diversificação do parque industrial ainda não diminuiu a 
hegemonia do agronegócio na composição do PIB industrial goiano.

Castro e Fonseca (1995) descrevem como o aumento da produção de grãos visto entre 1970 e 1980, em especial da soja, atraiu investimentos industriais para a região:

O deslocamento, durante pouco mais de uma década, de $40 \%$ da capacidade de produção de soja do país para as terras de Goiás, Mato Grosso e Mato Grosso do Sul, foi acompanhado, com uma defasagem de alguns anos, por grandes grupos voltados para atuação no mercado de commodities investindo na implantação de uma base de armazenamento, logo em seguida por inversões em atividades de esmagamento.

CASTRO; FONSECA (1995 P. 69)

A eficácia da implementação do POLOCENTRO na propagação de técnicas de cultivo e uso racional das terras pode ser observada pela evolução da utilização das terras apontada no gráfico 02, onde se faz o comparativo da situação em 1970 e em 2006, com acentuada redução das áreas destinadas a pastagens naturais (-84\%) e vertiginoso crescimento da área utilizada com pastagens plantadas (próximo a 300\%) e lavouras temporárias (próximo a 100\%). Estes dados demonstram a profissionalização da produção e intensificação da utilização de capital, principalmente ao se observar que não houve incremento da área total de utilização, denotando a substituição de pastagens naturais por pastagens plantadas e áreas de cultivo permanente e temporário (grãos).

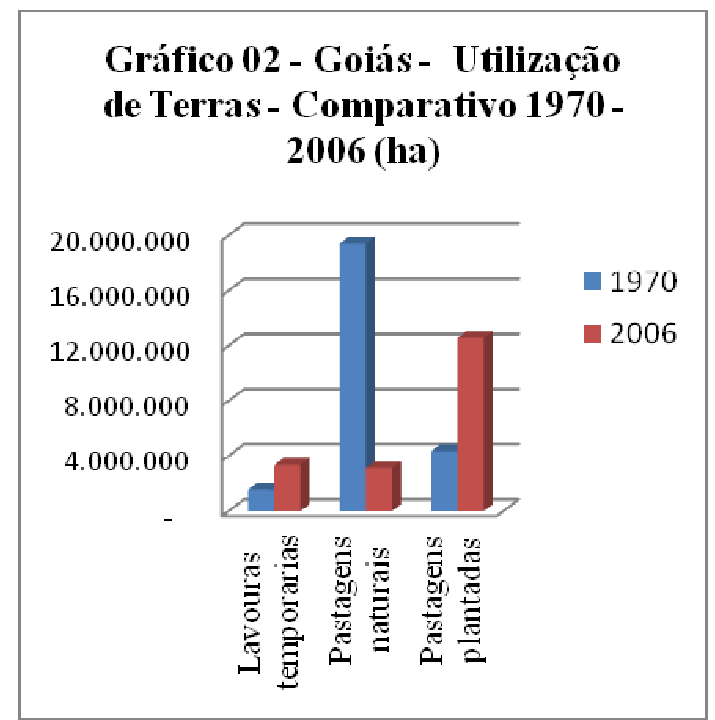

Fonte: IBGE, Censo Agropecuário 1920/2006 Adaptado pelo autor

Um reflexo importante da influência do aprimoramento do cultivo do solo do Cerrado trazido pelo POLOCENTRO e que coloca por terra a antiga afirmação de que Goiás não possuía aptidão para nada além da pecuária extensiva, são os níveis de produtividade das principais culturas geradoras de divisas, que em Goiás, conforme Tabela 02, tem suas médias superiores às médias nacionais.

Tabela 02 - Comparativo de Produtividade das Principais Culturas Agrícolas: Goiás-Brasil 2010

\begin{tabular}{l|c|c|c}
\hline \multirow{2}{*}{$\begin{array}{c}\text { Principais } \\
\text { produtos }\end{array}$} & \multicolumn{2}{c|}{$\begin{array}{c}\text { Rendimento } \\
\text { médio (kg/ha) }\end{array}$} & $\begin{array}{c}\text { Comparativo } \\
\text { c/ média } \\
\text { brasileira }\end{array}$ \\
\cline { 2 - 4 } & Goiás & Brasil & \\
\hline $\begin{array}{l}\text { Algodão herbáceo } \\
\text { (caroço) }\end{array}$ & 4.109 & 3.597 & $14 \%$ \\
\hline Feijão (em grão) & 2.428 & 1.035 & $135 \%$ \\
\hline Milho (em grão) & 5.562 & 5.012 & $11 \%$ \\
\hline
\end{tabular}




\begin{tabular}{l|c|c|c} 
Soja (em grão) & 2.966 & 2.635 & $13 \%$ \\
\hline Sorgo (em grão) & 2.493 & 2.948 & $-15 \%$ \\
\hline Cana de açúcar & 82.950 & 71.304 & $16 \%$ \\
\hline
\end{tabular}

Fonte: IBGE, Censo Agropecuário 1920/1996. Até 1996, dados extraídos de: Estatísticas do Século XX. Rio de Janeiro: IBGE, 2007 - Adaptado pelo autor.

\section{A análise da produção absoluta,} ressalta a importância deste setor goiano no cenário nacional, onde em 2010, segundo dados da SEGPLAN (2012) o estado ocupava o $4^{\circ}$ lugar nacional na produção de soja e de cana-de-açúcar, o $3^{\circ}$ lugar na produção de algodão e o $5^{\circ}$ lugar na produção de milho, posicionando-se como o $4^{\circ}$ maior produtor geral de grãos dentre os estados do Brasil, respondendo por quase $10 \%$ da produção nacional.

Na produção animal, Goiás também se destaca nacionalmente, possuindo, segundo dados da SEGPLAN/SEPIN (2012), o $4^{\circ}$ maior rebanho bovino, a $6^{\text {a }}$ maior produção de suínos e aves, além de ser a $3^{a}$ maior bacia leiteira do Brasil.

Quando se analisa a inserção de Goiás no cenário econômico internacional, novamente tem-se a agropecuária como principal componente das exportações goianas, sendo que as receitas derivadas desta área em 2012 teve a seguinte participação: $32,1 \%$ foi originária de exportações de soja, $20,5 \%$ de exportações de carnes e 12,3\% de exportações de milho, o que coloca estes três grupos da pauta de exportações como responsáveis por mais de $60 \%$ da receita nas transações do estado com o resto do mundo.

\section{Considerações Finais}

A partir da análise das informações obtidas no presente artigo verifica-se primeiramente que não há como dissociar o setor agropecuário do desenvolvimento do estado de Goiás, sendo que este setor da economia se mostrou fundamental para a dinâmica econômica do estado e se apresentará como tal por muito tempo, dada a aptidão para a agropecuária e a crescente demanda mundial por alimentos.

É sabido que o POLOCENTRO ou mesmo o II PND não foram os únicos programas governamentais responsáveis pela dinamização da agricultura e da economia goiana, havendo outros programas estatais tanto na esfera federal quanto nas esferas estadual ou municipal que contribuíram significativamente para o desenvolvimento e dinamização da agricultura e da economia goiana, porém o presente artigo objetivou o estudo deste programa em específico e sua associação com a atual conjuntura econômica do estado.

A comparação dos dados obtidos referente à utilização, no estado de Goiás, de áreas e produção absoluta de algumas culturas, quando restrita ao período 1970 e 1980, mostra que no intervalo de atuação do POLOCENTRO houve uma verdadeira modernização agrícola no estado de Goiás, com intensificação da produção comercial de grãos, introdução da cultura da soja em larga 
escala e o aumento do rebanho bovino, fomentando os alicerces para a atual plataforma agrícola e pauta de exportação local.

Verifica-se que o aprimoramento da aptidão agrícola do estado de Goiás deveu-se em boa parte ao II PND e ao POLOCENTRO, porém o período de implantação do programa coincide com outras iniciativas governamentais e empresariais que de alguma forma impactaram na situação atualmente vivida, assim, aceita-se parcialmente a hipótese de que o atual desenvolvimento de Goiás dependeu significativamente da iniciativa governamental aqui estudada, e a parcialidade na aceitação deve-se justamente à existência de outros programas paralelos.

Finalmente, verifica-se que ainda há espaço para expansão da atividade agrícola através da incorporação de áreas de pastagens, que ocupam quase três vezes a área cultivada por grãos, sendo que esta atividade que possui níveis de produtividade ainda maior que a atividade pecuária, que não seria interrompida, mas condensada em confinamentos a serem abastecidos por grãos produzidos em áreas que outrora serviam de pastagens, favorecendo e otimizando o uso do solo goiano.

\section{Bibliografia}

ALENCAR, G. O POLOCENTRO e o Desenvolvimento do Centro-Oeste. Brasília,
DF, 33 p. 1999. Disponível em www.ipea.gov.br, acesso em 13/07/2013.

BRASIL, Decreto 75.320/75 - Casa Civil da Presidência da República. Disponível em: www.planalto.gov.br.

CASTRO, Ana Célia, FONSECA, Maria da

Graça D. A dinâmica agro-industrial do Centro-Oeste. Brasília: IPEA, 1995.

DUARTE, T.M. O projeto de desenvolvimento do regime militar e o estado de Goiás. Revista OPSIS, n.09, UFG, Catalão, 2009

ESTEVAM, L. A.. O tempo da transformação: estrutura e dinâmica na formação econômica de Goiás. Campinas: IE / UNICAMP, 1997. (Tese de Doutorado).

GUIMARÃES, E.N.; LEME H.J.C. Caracterização Histórica e Configuração Espacial da Estrutura Produtiva do CentroOeste. NEPO n³3, Brasília-DF.

IBGE, Censo Agropecuário 1920/2006- 2007. Disponível em: http://seriesestatisticas.ibge.gov.br/. Acesso em 06/07/2013.

Indicadores. Levantamento

Sistemático da Produção Agrícola. Disponível em www.ibge.gov.br, acessado em 26/07/2013.

IMB/SEGPLAN - Instituto Mauro Borges de Estudos Socioeconômicos/Secretaria de Gestão e Planejamento do Estado de Goiás: Estado de Goiás: Características Socioeconômicas e Tendências Recentes. Estudos do IMB. Maio de 2013. 


\section{- Estado de Goiás no Contexto}

Nacional - 2011. Goiânia. 2012.

- Goiás em Dados, 2012.

Goiânia.

- Produto Interno Bruto do

Estado de Goiás (2010). 2012. Goiânia

SIMONSEN, R. História econômica do

Brasil. 8. ed. São Paulo : Cia Ed. Nacional, 1978.

SEGPLAN-GO / SEPIN / Gerência de

Estatística Socioeconômica - Jan/2012 